\title{
Positive psychiatry/ psychology for older adults: A new and important movement but robust methodology is essential.
}

\author{
Dr Charlotte R. Stoner, Research Department of Clinical, Educational and Health Psychology, \\ University College London (UCL)
}

\section{1-19 Torrington Place, London,WC1E 7HB, c.stoner@ucl.ac.uk}

Positive psychiatry and the related positive psychology are offering a much needed alternative framework through which to view the psychology of old age (Jeste, Palmer, Rettew \& Boardman, 2015). Traditional models of old age tend to approach the subject from a negative view point where themes of dependency and decline can be common (Cumming \& Henry, 1961). In contrast, positive psychiatry and psychology refer to the scientific study of strengths and capabilities that contribute to wellbeing (Seligman, 1998). Some of these can be thought of as character strengths and evidence suggests that concepts such as hope, humour, integrity and gratitude are universal, with examples documented in at least 54 nations across the world (Park, Peterson, \& Seligman, 2006). Researchers aligned to these theoretical models seek to explore complex approaches to measuring and improving mental health, recognising that wellbeing is often a dynamic interplay between positive and negative psychological processes and outcomes (Lomas \& Ivtzan, 2016).

For older adults, however, it seems that research regarding these positive concepts has been traditionally confined to qualitative examinations (e.g. Wolverson, Clarke, \& Moniz-Cook, 2016). Qualitative work is incredibly useful in exploring or delineating these often complex positive psychological concepts but, as is consistent with the approach of positive psychology, quantitative methodology is also needed. One such reason quantitative methodology is particularly needed is in the investigation of whether positive concepts are susceptible to influence. For example, there can be states versus traits debates and quantitative methodology may be an important means of capturing the degree to which concepts such as resilience can be learnt or are modifiable. Thus, to properly understand wellbeing for older adults, more quantitative research dedicated to assessing these positive processes and outcomes is needed.

Initiatives such as the Fountain of Health (FoH) described by Gough et al., (2018) are an example of shift towards positive outcomes oriented research. FoH is a multidisciplinary, 
non-profit organisation based in Canada and their aim is to promote well-being across the lifespan. To accomplish this goal, the FoH employed knowledge transfer methods for promoting healthy ageing and preventative lifestyle initiatives revolving around six modifiable factors: mental well-being and resilience, outlook on ageing, physical activity, social connection, cognitive activity and mental healthcare. Resources included educational videos, a speaker's bureau and self-guided educational tools and measures, which were available to healthcare providers and members of the general public. Participants were also encouraged to set S.M.A.R.T goals, a well-evidenced technique recently implemented in some National Health Service (NHS) settings in the UK (Shaw, Pattison, Holland, \& Cooke, 2015). Knowledge transfer materials could either be delivered in a one-to-one session or in a group format and these formats were tested for effectiveness and compared using a quality assurance framework. A total of 92 participants received the FoH knowledge transfer interventions; 51 within a group format and 41 as individuals. Evidencing the success of knowledge transfer, participants had a greater awareness of the FoH at post-test $(p<.001)$, and those participating individually had slightly greater awareness $(M=0.7)$ than those who took part within the group $(M=0.5)$. In addition, participants had a greater awareness of both mental health promotion interventions, the epigenetics of ageing and had a more positive self-perception of ageing. Fifty-three S.M.A.R.T goals were set, with 58.5\% of these goals met. The majority of these goals revolved around physical activity, a common theme for older adults and also encouraged by clinicians for avoiding unnecessary social care. (McNally et al., 2017). Confidence in goal setting, however, was not significantly different between pre and post-test. Differences between group and individual formats for each of the outcomes, although small, were apparent and it appears that FoH delivered in a group format by lay facilitators was the most effective format in terms of the outcomes explored.

Gough et al., (2018) have demonstrated that knowledge transfer interventions can be an effective means of promoting a healthy lifestyle for older adults and that these interventions can lead to improvements in other indices of wellbeing such as a more positive selfperception of ageing. Furthermore, by using a specific and measurable outcome such as goal setting, the authors were able to document the degree to which participants implemented aspects of intervention into their daily lives. The results suggest that such goals were readily made and met by participants. 
Positive interventions such as the $\mathrm{FoH}$, which focus on the promotion of physical and mental health have the potential to significantly improve the lives of older adults and are beginning to gain credence in the social sciences. Recent interventions for older adults have included those that focus on improving social connectedness (de Vlaming, Haveman-Nies, van't Veer, $\&$ de Groot, 2010) and one utilising positive psychology interventions such as the three good things intervention and a gratitude visit (Proyer, Gander, Wellenzohn, \& Ruch, 2014). However, as is keeping with positive psychology and psychiatry principles, robust methodology is needed, and findings reported by Gough et al., (2018) could be considered a first step in establishing the FoH knowledge transfer initiative as efficacious.

As the authors correctly draw attention to, there were limitations. The most substantial limitation of the current work was the lack of rigorous methodology. Whilst significant and positive outcomes were documented, these could be marginal at times and outcomes used were not robust. Problematically, the items used in the measure to capture awareness of FoH appeared to vary between formats, limiting the degree to which meaning can be assigned to significant outcomes. Of the other measures employed, little information or consideration of psychometric properties was given. This is also relevant for the non-significant confidence in goal setting result as it is unclear which, if any, established outcome measures were used for this particular outcome. Finally, facilitators also differed between formats with individual sessions delivered by a primary care clinician and a lay facilitator for the group format. Although both were trained to deliver FoH knowledge transfer interventions, existing and separate skills such as therapeutic alliance (Rogers, 1959) skills may have been more likely to occur in the individual format and influence results.

From a statistical perspective, randomised controlled trials (RCTs) are usually considered the gold standard for establishing effectiveness (Barton, 2000) but a more thorough consideration of the outcome measures employed is also needed. In particular, outcome measures should have documented and adequate psychometric properties for older adults and be theoretically related to the intervention, ensuring that the intervention in question is likely to produce effects on specific concepts measured. The authors should also make sure that behaviour change techniques are incorporated into their future work (Michie, van Stralen, \& West, 2011). This robust, quantitative methodology separates positive psychiatry and psychology from some humanist approaches that preceded them (Seligman \& Csikszentmihalyi, 2001) 
and is essential to ensure that interventions developed are done so using the best available evidence base.

Finally, whilst the researchers here chose not to include people living with dementia in their current project, they should not be routinely excluded from research such as this. People with dementia can face unique challenges and difficulties, however, there can still be a misconception that they lack the capacity for positive engagement or growth (Graham et al., 2003). Our recent body of research, during which we developed positive psychology outcome measures for older adults with mild dementia, suggests that they are equally capable of experiencing and articulating often complex concepts such as resilience (Stoner, Orrell, \& Spector, 2018a) and social engagement (Stoner, Orrell, \& Spector, 2018b), as described by Gough et al., (2018). Although knowledge transfer interventions may be challenging for people with dementia, due to the nature of the condition, this should not automatically exclude them and people with milder cognitive impairment could be supported to take part. Being diagnosed with dementia does not necessarily mean healthy ageing interventions are no longer relevant and part of challenging the narrative of dementia being solely a condition of decline for which little can be done (Vernooij-Dassen et al., 2005) will come from the type of research that is conducted and funded. By electing to fund and conduct research that focuses on maintaining or enhancing the strengths and capabilities that people with dementia retain, a powerful message is sent about what can constitute the lived experience of dementia.

The FoH initiative is an admirable endeavour to improve wellbeing across the lifespan. Knowledge transfer approaches such as those described by Gough et al., (2018) offer a relatively simple means of promoting evidence based interventions or lifestyle changes to prevent or delay disease. This has implications across the lifespan and knowledge transfer interventions could be easily adapted depending on the population for which it was employed. Both the individual and group format described led to some significant improvements and, important for the wellbeing of older adults, a significant improvement in positive perceptions of ageing was documented. This work could be described as a first step in establishing the interventions as effective but further evaluation by the $\mathrm{FoH}$ is needed. Future studies of the FoH knowledge transfer initiatives should include robust methodology and a careful consideration of the outcome measures employed. This will ensure that positive psychiatry or psychology interventions for older adults, as described here, are evidenced using the best possible methods. 


\section{References}

Barton, S. (2000). The best RCT still trumps the best observational study. BMJ, Sep13, doi: $10.1186 / 1471-2458-10-552$

Cumming, E., \& Henry, W. (1961). Growing Old. New York: Basic.

de Vlaming, R., Haveman-Nies, A., van't Veer, P., \& de Groot, L. C. P. G. M. (2010). Evaluation design for a complex intervention program targeting loneliness in noninstitutionalized elderly Dutch people. BMC Public Health, 10(1), 552. doi:10.1186/1471-2458-10-552

Gough, A., Cassidy, B., Rabheru, K., Conn, D., Canales, D. D., \& Cassidy, K. (2018). The Fountain of Health: effective health promotion knowledge transfer in individual primary care and group community-based formats. International Psychogeriatrics, May25, doi:0.1017/S1041610218000480

Graham, N., Lindesay, J., Katona, C., Bertolote, J. M., Camus, V., Copeland, J. R. M., . . . Wancata, J. (2003). Reducing stigma and discrimination against older people with mental disorders: a technical consensus statement. International Journal of Geriatric Psychiatry, 18(8), 670-678. doi:10.1002/gps.876

Jeste, D. V., Palmer, B. W., Rettew, D. C., Boardman, S. (2015). Positive psychiatry: Its time has come. Journal of Clinical Psychiatry, 76(6), 675-683. doi:10.4088/JCP.14nr09599.

Lomas, T., \& Ivtzan, I. (2016). Second Wave Positive Psychology: Exploring the PositiveNegative Dialectics of Wellbeing. Journal of Happiness Studies, 17, 1753-1768. doi:10.1007/s10902-015-9668-y

McNally, S., Nunan, D., Dixon, A., Maruthappu, M., Butler, K., \& Gray, M. (2017). Focus on physical activity can help avoid unnecessary social care. BMJ, 359. doi:10.1136/bmj.j4609 \%J BMJ

Michie, S., van Stralen, M. M., \& West, R. (2011). The behaviour change wheel: a new method for characterising and designing behaviour change interventions. Implementation Science, 6(42). doi:10.1186/1748-5908-6-42

Park, N., Peterson, C., \& Seligman, M. E. P. (2006). Character strengths in fifty-four nations and the fifty US states. The Journal of Positive Psychology, 1(3), 118-129. doi:10.1080/17439760600619567

Proyer, R. T., Gander, F., Wellenzohn, S., \& Ruch, W. (2014). Positive psychology interventions in people aged 50-79 years: long-term effects of placebo-controlled 
online interventions on well-being and depression. Aging \& Mental Health, 18(8), 997-1005. doi:10.1080/13607863.2014.899978

Rogers, C. (1959). A Theory of Therapy, Personality and Interpersonal Relationships as Developed in the Client-centred Framework. In S. Koch (Ed.), Psychology: A Study of a Science (Vol. 3, pp. 184-256). New York: McGraw Hill.

Seligman, M. E. P. (1998). The President's Address. Washington, DC: American Psychological Association.

Seligman, M. E. P., \& Csikszentmihalyi, M. (2001). Positive psychology: An introduction. American Psychologist, 55(1), 5-14. doi:10.1037//0003-066x.55.1.5

Shaw, R. L., Pattison, H. M., Holland, C., \& Cooke, R. (2015). Be SMART: examining the experience of implementing the NHS Health Check in UK primary care. BMC Family Practice, 16, 1-8. doi:10.1186/s12875-014-0212-7

Stoner, C. R., Orrell, M., \& Spector, A. (2018a). The Positive Psychology Outcome Measure (PPOM) for people with dementia: Psychometric properties and factor structure. Archives of Gerontology and Geriatrics, 76, 182-187. doi:10.1016/j.archger.2018.03.001

Stoner, C. R., Orrell, M., \& Spector, A. (2018b). Psychometric Properties and Factor Analysis of the Engagement and Independence in Dementia Questionnaire (EID-Q). Dementia and Geriatric Cognitive Disorders, 46(3-4), 119-127. doi:10.1159/000488484

Vernooij-Dassen, M. J. F. J., Moniz-Cook, E. D., Woods, R. T., Lepeleire, J. D., Leuschner, A., Zanetti, O., ... Iliffe, S. (2005). Factors affecting timely recognition and diagnosis of dementia across Europe: from awareness to stigma. International Journal of Geriatric Psychiatry, 20(4), 377-386. doi:10.1002/gps.1302

Wolverson, E. L., Clarke, C., \& Moniz-Cook, E. D. (2016). Living positively with dementia: a systematic review and synthesis of the qualitative literature. Aging \& Mental Health, 20(7), 676-699. doi:10.1080/13607863.2015.1052777 